Article

\title{
Variations in Moisture Supply from the Mediterranean Sea during Meteorological Drought Episodes over Central Europe
}

\author{
Milica Stojanovic *, Anita Drumond ${ }^{(\mathbb{D}}$, Raquel Nieto ${ }^{(\mathbb{D})}$ and Luis Gimeno \\ Environmental Physics Laboratory (EPhysLab), Facultade de Ciencias, Universidad de Vigo, 32004 Ourense, \\ Spain; anitadru@uvigo.es (A.D.); rnieto@uvigo.es (R.N.); l.gimeno@uvigo.es (L.G.) \\ * Correspondence: mstojanovic@uvigo.es; Tel.: +34-988-387-208 \\ Received: 6 June 2018; Accepted: 15 July 2018; Published: 19 July 2018

\begin{abstract}
The climate in Central Europe (CEU) during the 20th century is characterized by an overall temperature increase. Severe and prolonged drought events began occurring towards the end and these have continued into the 21st century. This study aims to analyze variations in the moisture supply from the Mediterranean Sea (MDS) during meteorological drought episodes occurring over the CEU region over the last three decades. A total of 51 meteorological drought episodes (22 with summer onsets, and 29 with winter) are identified over the CEU during the period 1980-2015 through the one-month Standardized Precipitation Evapotranspiration Index (SPEI-1), and their respective indicators, including duration, severity, intensity, and peak values, are then computed. Lagrangian forward-in-time analysis reveals that negative anomalies of moisture coming from the MDS prevail in all episodes except seven. Linear regression analysis between variations in the MDS anomalies and indicators of the drought episodes shows a significant linear relationship between severity, duration, peak values (winter), and MDS anomalies, which implies that drought episodes last longer and are more severe with an increase in the negative anomaly of moisture supply from the MDS. Nevertheless, no linear relationship is found between the intensity and peak values (annual, summer) of drought episodes and anomalies in the moisture contribution from the MDS.
\end{abstract}

Keywords: drought; SPEI; Lagrangian method; Central Europe; Mediterranean Sea

\section{Introduction}

Hydrological cycle elements (precipitation (PRE), evaporation and moisture transport) have become some of the most important themes in current climate variability research and change evaluation [1]. Climate change influences not only average temperatures, but also the frequency of extreme events affecting natural and human systems [2]; the Intergovernmental Panel on Climate Change (IPCC) assessment report [1] on extreme events confirmed that climate change would cause changes in the intensity, severity and duration of extreme events, and would thus present severe risks to both humans and the environment. In this respect, several studies have highlighted the role of recent climate change in increasing the probability of occurrence of extreme events, such as drought [3-5]. Europe is likely to experience diverse impacts on response to climate change, such as temperature increases and variability in extreme events [6], and many European countries have experienced episodes of drought over the past 30 years that have caused significant ecological and economic damage [7]. Droughts are difficult to predict due to the complexity of contributions to their occurrence, but continuous drought monitoring is imperative.

Several authors have shown that a PRE deficit combined with high evapotranspiration typically leads to drought [8-11], and PRE deficits in some areas have been found to be related to changes in 
moisture transport $[8,12,13]$. Therefore, it is important to examine mechanisms responsible for PRE deficits over sinks, or mechanisms related to any reduction in evaporation from the source that causes drought in certain regions.

Many drought indices have been developed to monitor, predict, and assess the severity of drought, such as the Reconnaissance Drought Index (RDI) [14], the Streamflow Drought Index (SDI) [15], the Palmer Drought Severity Index [16], the Standardized Precipitation Index (SPI) [17], the Standardized Precipitation Evapotranspiration Index (SPEI) [18], the Standardized Indices through Non-Parametric Rescaling (SINRes) [19]. Computations of the SPEI and SINRes consider both PRE and potential evapotranspiration (PET). Indirectly, temperature is taken into account, given that it is used in the computation of potential evapotranspiration. The SPEI has been extensively applied in studies around the world, such as in America [20,21], Asia [22,23], Africa [24,25] and Europe [26-30].

Several studies have investigated the relationship between sources and sinks of moisture and drought in specific regions [24,31-33] The Lagrangian techniques have been widely utilized for identifying the sources of atmospheric moisture for continental areas (e.g., [34-37]). In comparison to the other approaches, such as the Eulerian technique "numerical water vapor tracers" [38,39], "analytical and box models" [40,41], and "physical water vapor tracers" (isotopes) [42], the Lagrangian approach $[36,37,43,44]$ is one of the most suitable tools for establishing a source-sink relationship of the atmospheric moisture transport, as pointed out by Gimeno et al. [34].

Previous authors investigated the origin and destination of moisture over the Mediterranean region using different techniques. Fernandez et al. [45] applied a Eulerian method by integrating the vertical moisture flux over the Mediterranean Basin and Southern Europe using meteorological reanalysis from the National Centers for Environmental Prediction (NCEP). However, this method cannot provide information about the origin of moisture reaching the basin and the destination from it. Applying a Lagrangian approach over a 5-year period of data, Nieto et al. [46] and Schicker et al. [47] computed the budget of evaporation minus PRE in air masses tracked backward-in-time from the Mediterranean Basin to identify the main moisture sources; and also computed the moisture contribution from this region to surrounded continental regions by tracking forward-in-time air masses. Drumond et al. [48] extended the work of Nieto et al. [46] by focusing on the seasonal variations in moisture sources for different Mediterranean target regions during drier and wetter years. The long-term variability of the main climatological moisture sources for eight target regions in the Mediterranean Basin was investigated by Gómez-Hernández et al. [49] using the ERA-40 reanalysis dataset. Applying a different Lagrangian approach, Sodemann et al. [50] analyzed seasonal and interannual variability of the moisture sources for the Alpine PRE during 1995-2002, showing the importance of the Mediterranean as the source of moisture for PRE events.

The Mediterranean Sea (MDS) was identified as the main moisture source for Central and Eastern Europe (CEU, Figure 1) and the surrounding basin area, and changes in its moisture supply have an impact on dryness conditions in regions where moisture sinks [33,38,45,47,50-52]. Using the Lagrangian approach developed by Stohl and James [36,37], Drumond et al. [33] investigated whether severe dry conditions accumulated during the extended winter and summer seasons over the climatological moisture sinks of the MDS were associated with changes in moisture transport from the basin. Focusing on meteorological droughts, Stojanovic et al. [13] recently investigated anomalies in the moisture supply during the 2003 episode in Europe. However, further and deeper exploration is required to determine the existence of a climatological relationship between changes in the moisture supply from the MDS and meteorological drought episodes over the CEU.

The CEU region, according to the definition proposed in the 5th Assessment Report (AR5) of the IPCC [4] (Figure 1), comprises Germany, Switzerland, Liechtenstein, Austria, Poland, the Czech Republic, Slovakia, and Hungary. The climate is humid continental-type with cool summers. This is a region, where Atlantic, Mediterranean, and continental influences meet and complex orography has a significant impact on the climate and meteorology in the region [53]. 


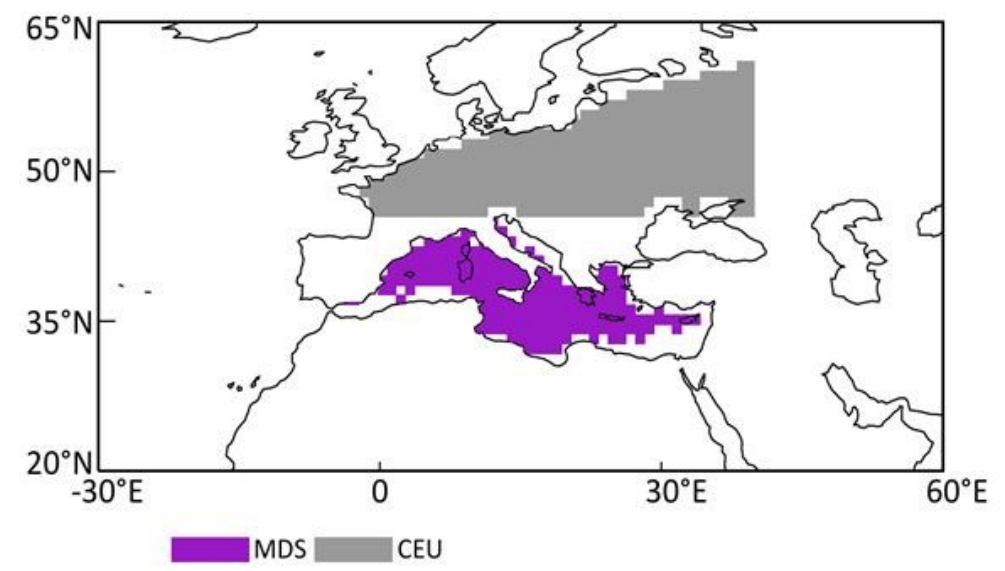

Figure 1. Central and Europe region (CEU, grey) with boundaries defined from the 5th Assessment Report (AR5) of the Intergovernmental Panel on Climate Change (IPCC), with the Mediterranean Sea (MDS, purple color) source identified using a backward-in-time experiment according to Stojanovic et al. [13].

This study therefore analyzes variations in the moisture transport from the MDS during meteorological drought episodes over the CEU (Figure 1) for the period (1980-2015), and aims to determine whether anomalies of this contribution have different effects on episodes with onsets during winter and summer seasons. The main goals are: (1) to identify meteorological drought episodes over the CEU during 1980-2015 through the one-month Standardized Precipitation Evapotranspiration Index (SPEI-1) [18]; (2) to use Lagrangian methodology to analyze the anomalous contribution from the MDS to the CEU region during drought episodes [36,37], and to check possible links between variations in moisture supply and indicators of selected episodes through linear regression analysis. This study focuses on the meteorological droughts episodes over the CEU, therefore differing from the previous analysis of dry conditions accumulated during the extended seasons over the Mediterranean sinks, which was developed by Drumond et al. [33]. Section 2 explains the data and methods; Section 3 presents results and discussion; and Section 4 provides conclusions.

\section{Data and Methodology}

\subsection{Data}

The analyses were carried out using a climatology of 36 years (1980-2015). The Lagrangian model is forced by the ERA-Interim global reanalysis dataset from the European Centre for Medium-Range Weather Forecasts (ECMWF) [54], which is available at a spatial resolution of $1^{\circ} \times 1^{\circ}$ on 61 vertical levels from the surface to $0.1 \mathrm{hPa}$. The dataset can be retrieved at (https://www.ecmwf.int/en/ forecasts / datasets/archive-datasets/reanalysis-datasets/era-interim). Lorenz and Kunstmann [55] found that the ERA-Interim reanalysis data provide a superior performance in reproducing the hydrological cycle and a relatively reasonable closure of the terrestrial and atmospheric water balance, compared to reanalysis datasets, such as Modern Era Retrospective-Analysis for Research and Applications (MERRA) [56], and Climate Forecast System Reanalysis (CFSR) [57]. These findings thus support the use of ERA-Interim datasets for our study, since the Lagrangian model requires high-quality data for wind and humidity [58].

Datasets of PRE and PET were available at a spatial resolution of $0.5^{\circ}$ from the Climate Research Unit (CRU) Time-Series (TS) Version 3.24.01 [59]. We calculated the time series of PRE and PET over the CEU, information required to compute the SPEI. Data are available at https:/ / crudata.uea.ac.uk/ $\mathrm{cru} /$ data/hrg/cru_ts_3.24.01/cruts.1701201703.v3.24.01/.

The climatological annual cycle of PRE, PET and the moisture contribution from the MDS to the CEU during 1980-2015 (Figure 2) revealed that the contribution from the MDS to the CEU was 
higher from September to December. In terms of the climatological annual cycle of the freshwater flux (PET-PRE), PRE prevailed over PET during the winter season (from October to March), indicated as (PET-PRE) $<0$, while the inverse pattern was configured as (PET-PRE) $>0$ during summer (from April to September).

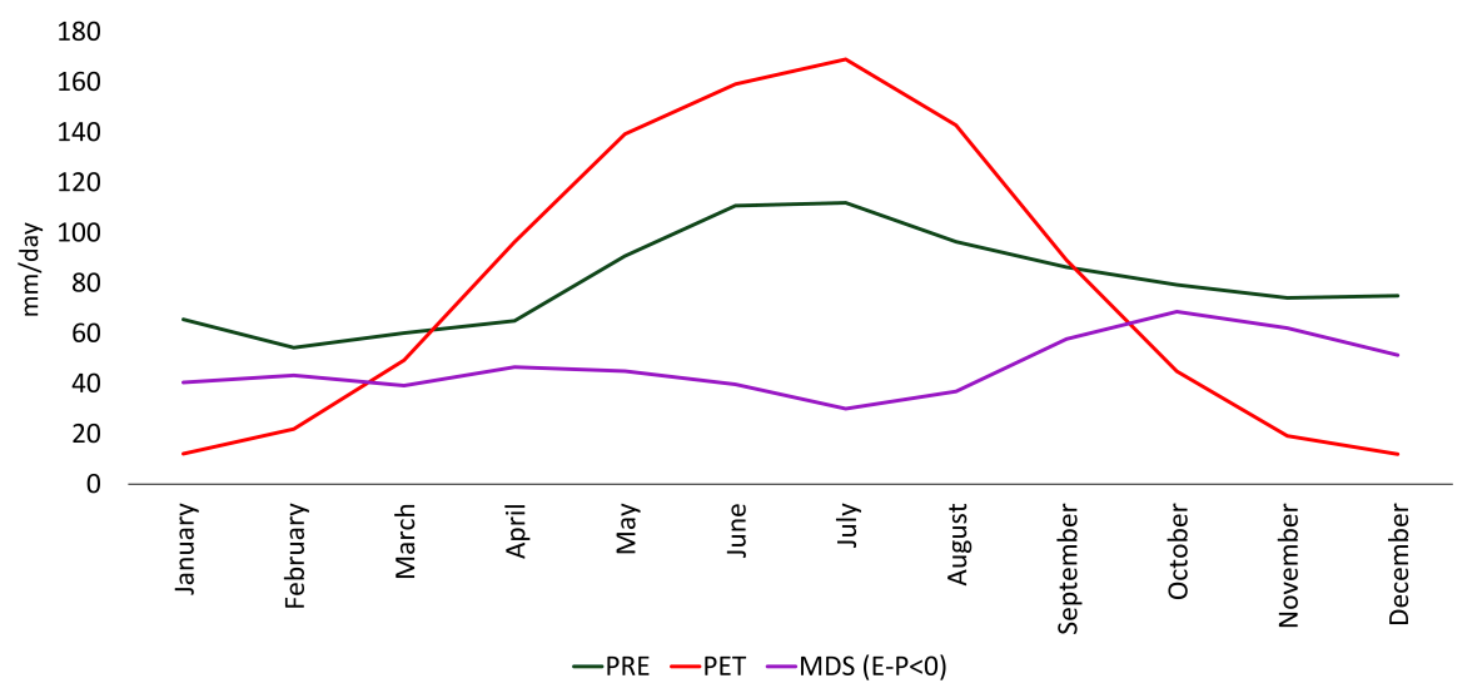

Figure 2. Climatological annual cycle of precipitation (PRE, $\times 10$ green line), potential evapotranspiration (PET, $\times 10$ red line) (data from the Climatic Research Unit (CRU) (TS3.24.01) (scale: mm/day) values integrated over the CEU), with the moisture contribution from the MDS (purple color ( $\mathrm{mm}$ /day) values integrated over the CEU) to the CEU obtained via the forward experiment.

Evaporation data for the calculation of monthly anomalies of the evaporation rate over the MDS were obtained from the Objectively Analyzed air-sea Heat Fluxes (OAFlux) project [60], while monthly anomalies of vertical velocity (omega) at $500 \mathrm{hPa}$ averaged during each meteorological drought episode identified over the CEU were calculated using the ERA-Interim dataset [54].

\subsection{Standardized Precipitation Evapotranspiration Index (SPEI)}

The SPEI is based on the monthly climatic water balance (PRE minus PET) calculated at various time scales (i.e., accumulation over given time intervals), and the resulting values are adjusted to a log-logistic probability distribution to convert original values to standardized units that are comparable in space and time at different SPEI timescales [18]. Other probability distributions could be applied, for instance, based on general extreme values (GEV) [61,62], but SPEI's developers recommended the use of the first one, due to the fact that the differences between both distributions are marginal for climate analysis [63]. For the purpose of this study, the crucial advantage of SPEI over other commonly used drought indices (such as the PDSI [16] and the SPI [17]) is the role of temperature, which is considered through PET values. In addition, the multiscalar characteristics of SPEI permit the identification of different types of drought $[64,65]$, and a complete comparison of indices has been provided in previous studies $[18,66,67]$.

This study used the one-month Standardized Precipitation Evapotranspiration Index (SPEI-1) to identify meteorological drought episodes occurring over the CEU region during the period 1980-2015. The SPEI at different timescales corresponds to different drought types, such as 1-2-month SPEI for meteorological drought (e.g., [18]). Following Liu et al. [68] the SPEI-1 was chosen in this study because we were interested in the variability of water vapor transport, which is closely related to meteorological drought. Several works used SPEI-1 or SPI-1 for the same aim of this short note over other areas, as in Southwest China [68] and Europe (e.g., [69,70]). In SPEI-1, respective values were accumulated during a one-month period, and the drought index was calculated using monthly CRUTS 3.24.01 data of PRE 
and PET averaged over the CEU region. We have also calculated the SPI-1 time series for the CEU during 1980-2015 with the same CRU data. The temporal evolution of SPEI-1 and SPI-1 was similar (not shown), with a coefficient of correlation of 0.96 . Although the SPI showed slightly higher peaks, the onset and dismissal of drought episodes identified through both series were the same.

Episodes were identified in concordance with the criteria of McKee et al. [17]: the start of an episode was determined when the SPEI-1 value first fell below zero followed by a value of -1 or less, and the end was decided when the SPEI- 1 value returned to a positive value. After identifying events, their indicators were computed with respect to severity, duration, intensity and peak values, where severity represents the absolute value of the sum of all SPEI values during the episode, duration signifies the number of months between the first and last months of the episode, intensity is calculated as the ratio between severity and duration and peak values are the most negative values registered [71,72]. Because the purpose of this study was to analyze the relationship between the indicators of the episodes and the MDS moisture contribution under a climatological perspective, this period was classified as a drought event, even when the SPEI remained negative only for a month. The episodes were also organized into two groups according to their onset: summer (April-September) and winter (October-March).

\subsection{The Lagrangian Approach}

The Lagrangian FLEXible PARTicle dispersion model (FLEXPART) developed by Stohl and James $[36,37]$ was used to investigate anomalies in the moisture supply from the MDS during drought episodes occurring over the CEU during 1980-2015.

In the FLEXPART simulation, the atmosphere is divided uniformly into approximately 2 million particles over the entire globe. A constant mass is considered for each particle as it is transported using 3D wind fields. Particles are identified every six hours, and the transport time is limited to 10 days, which reflects the mean water vapor lifetime in the global atmosphere [73]. The moisture variations presented by a particle during its trajectory can be calculated through variations in specific humidity: $e-p=m(d q / d t)$, where $m$ is the mass of the particle and $(e-p)$ (evaporation minus PRE) represents the freshwater flux associated with the particle. Knowing the specific humidity in every time step, it is possible to identify particles that lose moisture through PRE $(p)$, or obtain it through evaporation $(e)$. Adding $(e-p)$ for all the particles residing in an atmospheric column over the area, it is possible to obtain the total freshwater flux $(\mathrm{E}-\mathrm{P})$. The trajectory of the particles can be advected using backward-in-time analysis with the aim of determining the sources of moisture for the target region $(\mathrm{E}-\mathrm{P}>0)$ or forward-in-time analysis to investigate where moisture sinks after being transported by particles $(\mathrm{E}-\mathrm{P}<0)$. More detailed information about the functionalities of FLEXPART can be found in Stohl and James [36,37] and Gimeno et al. [34].

The main advantage of the model is that it enables backward and forward tracking of air masses over time, and enables an analysis of the water balance in the atmospheric column along the trajectories. Nevertheless, this approach has two main limitations, according to Stohl and James [36,37]: the first is that it is not possible to individually diagnose $\mathrm{E}$ and $\mathrm{P}$, and the second is that results are highly reliant on input data quality. In addition, fluctuations in specific humidity (q) along trajectories may occur for nonphysical reasons, due to the interpolation of q or trajectory errors; however, this limitation can be compensated for by the large numbers of particles that are contained in an atmospheric column over a given area. A more detailed description of backward and forward analyses can be found in a number of studies that have applied this model to estimate humidity changes along trajectories and identify sources of moisture and sinks in many different regions worldwide, such as the Danube River Basin [74], the Congo River Basin [32], Central America [75], the Mediterranean region [48], Iceland [76], the Fertile Crescent region [24] and the Indus, Ganges, and the Brahmaputra River Basin [77]. Furthermore, Stojanovic et al. [13] recently applied this method to investigate anomalies in the moisture supply during the 2003 drought episode in Europe. 
In this study, we considered the MDS as the source of moisture for the CEU (Figure 1) and calculated the anomalous contribution from this source to the CEU region during drought episodes identified in the period 1980-2015. The monthly anomaly was computed as the difference of the monthly average with respect to the respective monthly climatological mean. Then, the monthly anomalies were accumulated during each episode. Forward analysis was used to calculate monthly anomalies (accumulated during each episode) from the MDS integrated over the CEU region.

\subsection{Linear Regression Analysis}

Using Simple Linear Regression, we calculated the coefficient of determination $\left(R^{2}\right)$ with the linear regression equation, which represents the proportion of the variance in the dependent variable (severity, duration, intensity, and peak values of drought) that is predictable with respect to the independent variable (contribution from the MDS source). The linear regression analysis was conducted to verify whether variations in the contribution from the MDS to the CEU may affect the indicators of drought episodes. The student $t$-test and the Spearman rank correlation coefficient [78] at a 95\% significance level were also applied to confirm the statistical significance of the regression coefficient.

\section{Results and Discussion}

\subsection{Analysis of Drought}

Figure 3 shows the SPEI-1 time series for the CEU during the period 1980-2015, in which the negative values (red bars) represent dry conditions and the positive ones (blue bars) represent wet conditions. We identified 51 meteorological drought episodes (22 with onsets during summer and 29 with winter onsets) and ranked these according to severity, duration, intensity and peak values. The results are shown in Table S1 in Supplementary Materials, from which it is evident that the most severe drought episode occurred from February to June 2003 (with a value of 7.1). The second most-severe event occurred in June-October 2015 (6.45), during which time the maximum peak was reached. Furthermore, the longest drought episode lasted for seven months from June to December 1983, while the most intense occurred during October 1995 (2.16) and lasted for only one month.

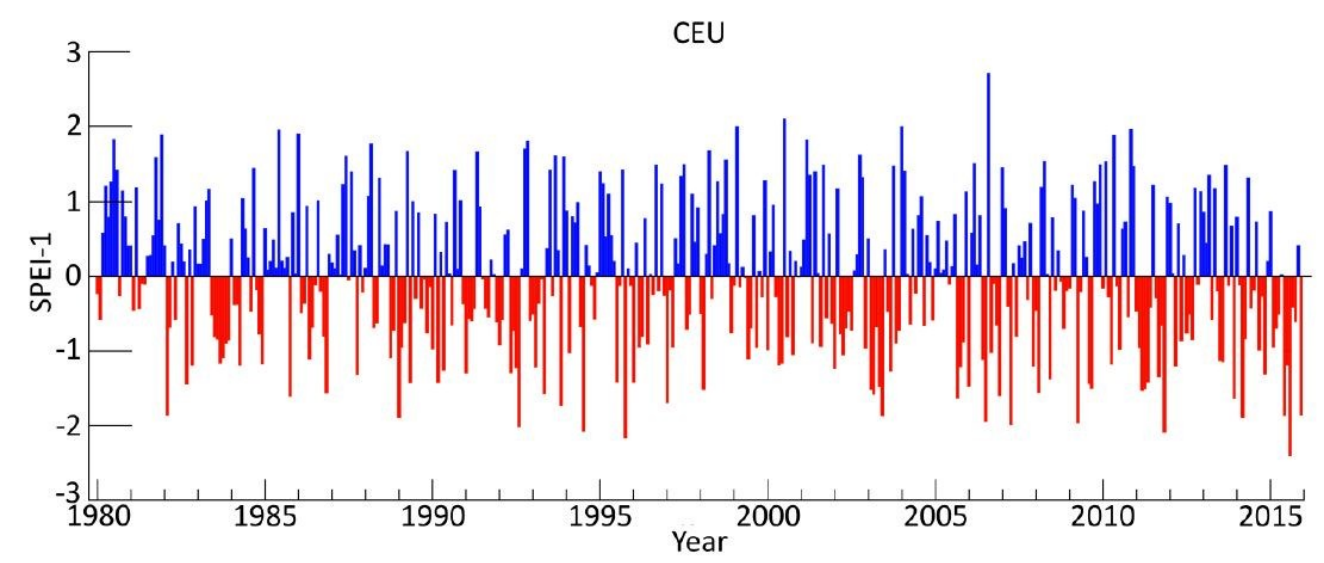

Figure 3. Time series of one-month Standardized Precipitation Evapotranspiration Index (SPEI-1) for the CEU region during 1980-2015. Blue and red bars represent positive and negative values, respectively.

\subsection{Monthly Anomalies of Evaporation, Vertical Velocity (Omega) and Moisture Supply}

Monthly anomalies of evaporation, vertical velocity (omega) and moisture contribution from the MDS to the CEU region accumulated during each drought episode identified in 1980-2015 are shown in the Figure 4. Results showed that the signal of the anomalies of evaporation over the MDS 
varied during the episodes, although there was a predominance of the negative anomalies (Figure 4, black line). From the 51 episodes selected, 31 events were associated with reduced evaporation over the MDS (60.8\% of the cases), in contrast to the 20 events related with increasing evaporation over the MDS (39.2\% of the cases). Regarding some seasonal patterns, from the 29 drought episodes with onsets during winter, a reduction in the evaporation over the MDS was evident in 19 events, while only 10 presented increased evaporation in the basin. Nevertheless, this reduction was not so evident for the episodes with onset in summer: from the 22 events, 12 were associated with reduction in the MDS evaporation, and 10 were related with increasing evaporative conditions over the MDS.

Based on the contribution from the MDS to the CEU, we could see that with the exception of seven drought episodes (red bars) occurring in November 1982, May 1990, July-August 1995, December 1995-January 1996, October 2000, March-April 2010, and June-October 2015, negative anomalies of MDS prevailed for almost all drought episodes (blue bars). Only the episode occurring from June to October 2015 was one of the five longest and most severe episodes of all recorded, whereas the remaining six drought episodes had severity rankings between the 14 least severe episodes ever recorded in the period (Table S1, Supplementary Materials). The most intensely negative anomalies of moisture supply from the MDS occurred during January-June 2011 (103.55 mm/day), January-December 1983 (100.7 mm/day), September-December 2006 (92.08 mm/day), February-June 2003 (91.95 mm/day) and August-November 2011 (89.92 mm/day) drought episodes. These drought episodes were among the 11 longest and most severe episodes of all recorded. Except for one case with conditions associated with inhibition of local PRE (Figure 4, green line), anomalous atmospheric subsidence prevailed over the CEU during the episodes.

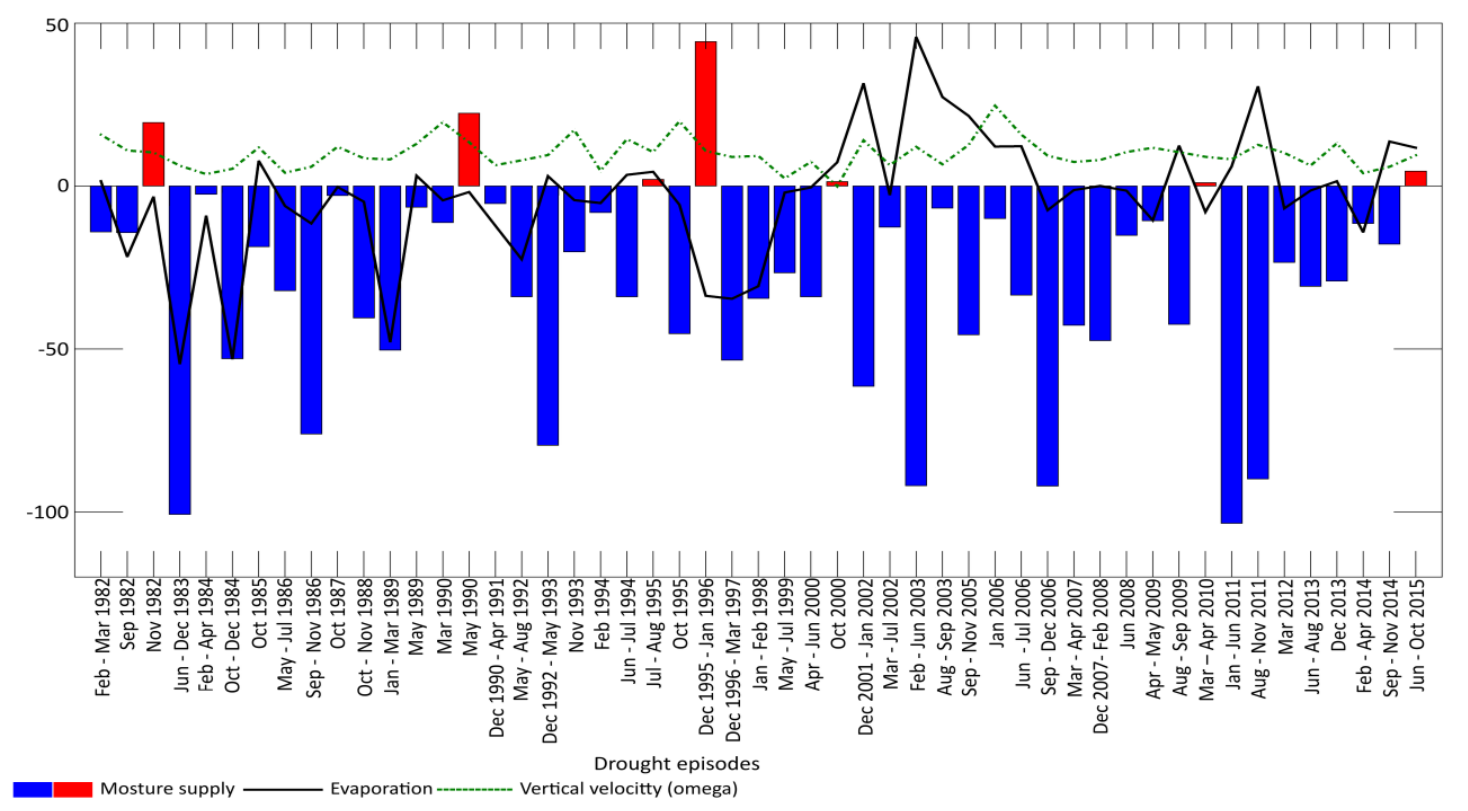

Figure 4. Monthly anomalies of the evaporation rate over the MDS ( ${ }^{*} 10 \mathrm{~mm} /$ day, black line), the vertical velocity (omega) at $500 \mathrm{hPa}(/ 1000 \mathrm{~Pa} / \mathrm{s}$, green line) and the moisture supply from the MDS (mm/day, blue and red bars) accumulated during each meteorological drought episode identified over the CEU during the period 1980-2015.

Although we were not able to verify possible alternative destinations of the moisture evaporated over the MDS from this analysis, it is evident that the moisture supply from the MDS to the CEU was reduced during the CEU meteorological episodes, which may be associated with the reduction in the MDS evaporation, particularly during the cases with onsets during winter. It is known from previous works (e.g., [33] and references therein) that the regions most affected by moisture transport from the MDS are the CEU and the Eastern Mediterranean, and it would be of further interest to analyze 
how the moisture transport towards these climatological sinks was affected during the meteorological drought episodes of the CEU.

\subsection{Linear Regression Analysis}

To determine the existence of a linear relationship between the different indicators of drought episodes (severity, duration, intensity and peak values) and variations in contributions from the MDS, a Simple Linear Regression analysis was conducted using the Least Squares Method (Figure 5). Analysis was conducted for the entire period and was then repeated for events with onsets in winter (October-March) and in summer (April-September). The coefficient of determination was computed to determine representativeness of the analysis, and the student $t$-test at a $95 \%$ confidence interval was applied to the regression coefficient to determine statistical significance. Table 1 shows the significance (a significance level of $95 \%$ ), slope, intercept and coefficient of determination $\left(R^{2}\right)$ for the severity, duration, intensity and peak values with MDS anomalies on annual, winter and summer scales.

According to the student $t$-test statistic applied here, a significant linear relationship was shown to exist between the severity, duration, peak value (winter season) and the MDS anomalies. This implied that episodes, which were more severe and longer, and had peaks that were more intensive, were associated with more intensively negative moisture supply anomalies from the MDS (accumulated during the episode). However, no linear relationship was determined between the intensity and peak value of drought episodes (the whole period, summer season) and moisture contribution anomalies from the MDS. The highest coefficient values of determination $\left(R^{2}\right)$ occurred between severity and MDS anomalies during winter (0.53), which meant that $53 \%$ of variability in the severity of drought episodes could be explained by variations in moisture supply anomalies from the MDS. Although $\mathrm{R}^{2}$ for the severity of drought episodes for the whole period (0.38) and severity of episodes beginning during summer (April-September) (0.22) were less than those for episodes beginning in winter (October-March), the analysis showed a significant linear relationship. The duration of episodes was also associated with variations in MDS supply anomalies with $R^{2}$ of 0.35 for the entire period; $R^{2}$ was increased slightly to 0.39 for episodes with summer onsets only; and $\mathrm{R}^{2}$ was reduced to 0.31 for winter episodes. Results from a Spearman's rank correlation analysis (not shown) corroborated the regression analysis presented here through a non-parametric approach [79].

The Simple Linear Regression analysis was repeated after classifying droughts as a short and a medium terms based on duration (duration less than or equal to 3 months is a short-term episode, while duration greater than 3 months corresponds to a medium-term event), and also as mild and severe/extreme based on peaks (peaks that are less intensive than -1.5 are mild, and peaks that are more intensive than -1.5 are severe/extreme [17]), and results are shown in Tables S2 and S3 of Supplementary Materials. Although the occurrence of medium-term episodes prevailed over the short-term ones (40 and 11, respectively), the linear association between the severity and moisture supply was mainly preserved for the short-term episodes. Only the severity of the medium-term episodes with onsets in winter was linearly associated with the variability in the moisture supply. The linear association between the duration and moisture supply was preserved for all short-term episodes observed during the year, and also for the short-term ones with onsets in summer. For the remaining properties of the episodes (intensity and peak), only the intensity of the medium-term episodes with onsets in summer was linearly associated with variations in the moisture supply from the MDS. Concerning the episodes classified based on peaks, the occurrence of severe/extreme episodes prevailed over the mild ones ( 39 and 12, respectively), and the linear association between the severity, as well as duration, and moisture supply persisted only for the severe/extreme episodes, given all severe episodes, as well as the ones with onsets during winter were considered. 
a)

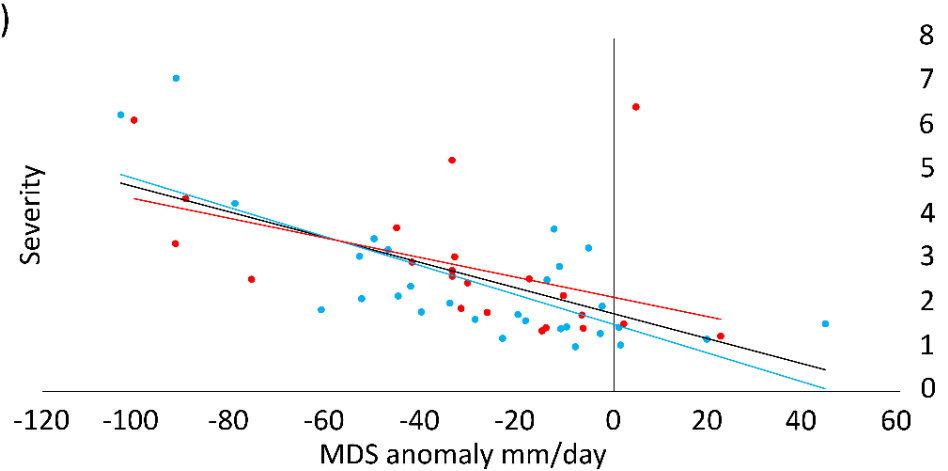

b)

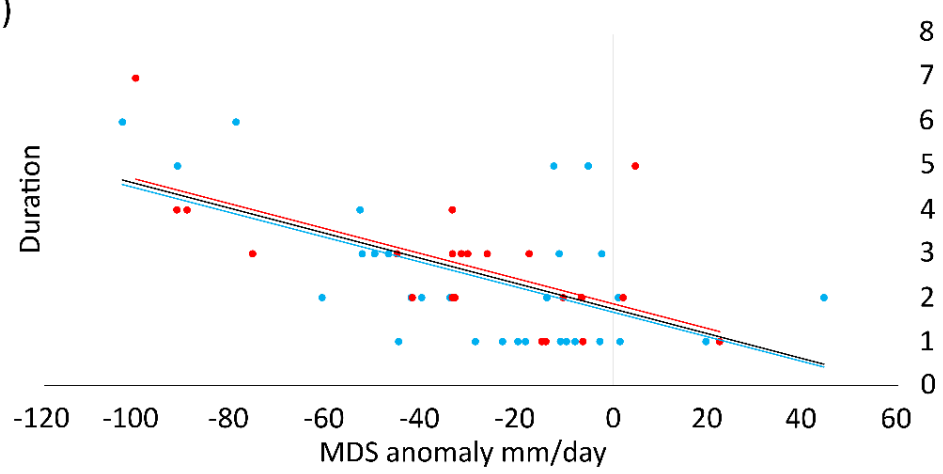

c)

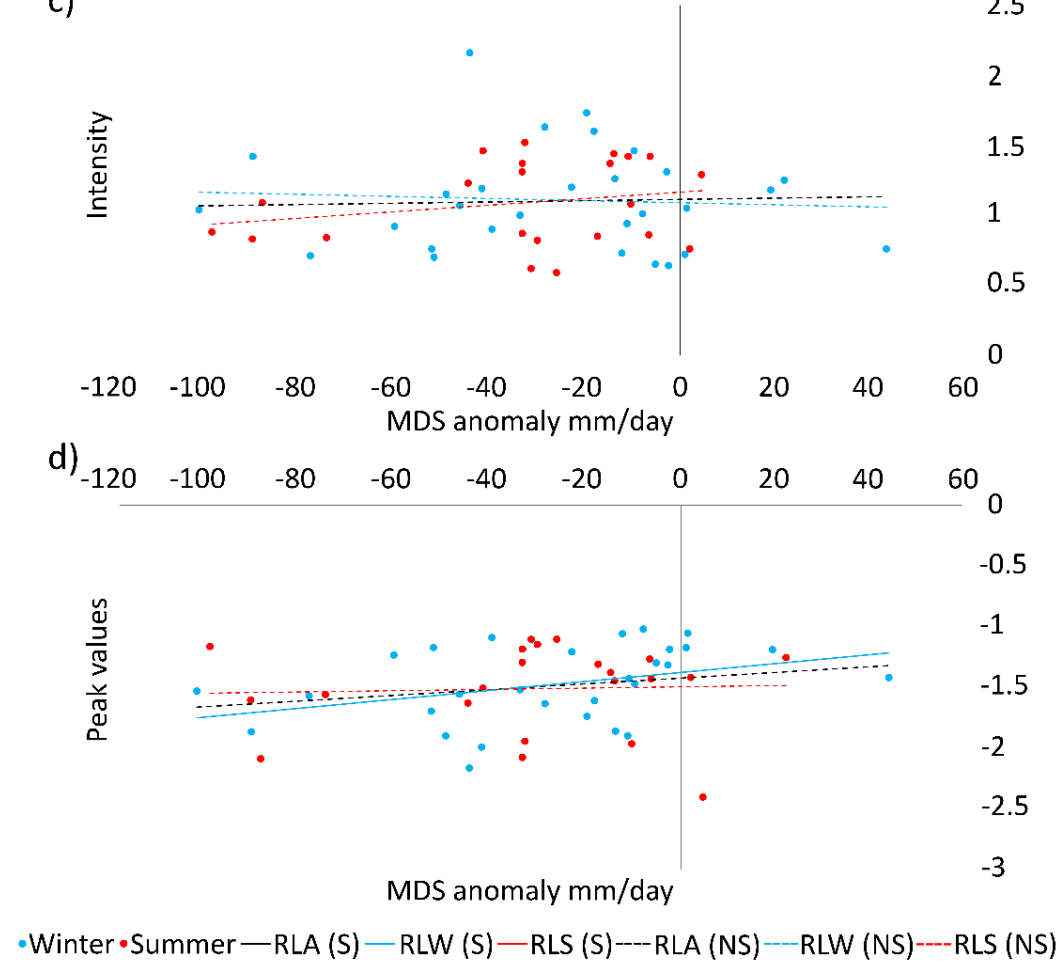

Figure 5. Scatterplot: moisture supply anomalies from the MDS (x-axis, $\mathrm{mm} /$ day) and the severity (a); duration (b); intensity (c) and peak values (d) of drought episodes at the annual (entire period shown by both blue and red dots), onsets in winter (March-October) (blue dots) and summer (April-September) (red dots) scales. Corresponding regression lines are also shown: RLA (S) represents Regression Line Annual Significant; RLW (S) represents Regression Line Winter Significant; RLS (S) represents Regression Line Summer Significant; RLA (NS) represents Regression Line Annual Nonsignificant; RLW (NS) represents Regression Line Winter Nonsignificant; and RLS (NS) represents Regression Line Summer Nonsignificant. 
Table 1. The significance (a significance level of $95 \%$ ), slope, intercept and coefficient of determination $\left(R^{2}\right)$ for severity, duration, intensity and peak values with respect to MDS anomaly on annual, winter and summer scales. Underlined bold numbers represent a significant linear relationship with MDS anomaly.

\begin{tabular}{ccccccccccc}
\hline & \multicolumn{3}{c}{ Annual } & \multicolumn{3}{c}{ Winter } & \multicolumn{3}{c}{ Summer } \\
\hline & Slope & Intercept & $\mathbf{R}^{\mathbf{2}}$ & Slope & Intercept & $\mathbf{R}^{2}$ & Slope & Intercept & $\mathbf{R}^{2}$ \\
\hline $\begin{array}{c}\text { Severity } \times \\
\text { MDS anomaly }\end{array}$ & $\underline{\mathbf{- 0 . 0 2 8 6}}$ & $\underline{\mathbf{1 . 7 5 8 0}}$ & $\underline{\mathbf{0 . 3 8 6 0}}$ & $\underline{-\mathbf{0 . 0 3 2 8}}$ & $\underline{\mathbf{1 . 5 1 5 0}}$ & $\underline{\mathbf{0 . 5 3 1 4}}$ & $\underline{-\mathbf{0 . 0 2 2 2}}$ & $\underline{\mathbf{2 . 1 3 1 0}}$ & $\underline{\mathbf{0 . 2 2 7 6}}$ \\
\hline $\begin{array}{c}\text { Duration } \times \\
\text { MDS anomaly }\end{array}$ & $\underline{\mathbf{- 0 . 0 2 8 4}}$ & $\underline{\mathbf{1 . 7 4 2 0}}$ & $\underline{\mathbf{0 . 3 5 0 8}}$ & $\underline{\mathbf{- 0 . 0 2 8 1}}$ & $\underline{\mathbf{1 . 6 6 5 0}}$ & $\underline{\mathbf{0 . 3 1 6 7}}$ & $\underline{\mathbf{- 0 . 0 0 2 8 2}}$ & $\underline{\mathbf{1 . 8 5 7 0}}$ & $\underline{\mathbf{0 . 3 9 8 7}}$ \\
\hline $\begin{array}{c}\text { Intensity } \times \\
\text { MDS anomaly }\end{array}$ & 0.0004 & 1.1120 & 0.0018 & -0.0007 & 1.0890 & 0.0044 & 0.0023 & 1.1640 & 0.0520 \\
\hline $\begin{array}{c}\text { Peak values } \times \\
\text { MDS anomaly }\end{array}$ & 0.0023 & -1.4200 & 0.0487 & $\underline{\mathbf{0 . 0 0 3 6}}$ & $\underline{\mathbf{- 1 . 3 7 3 0}}$ & $\underline{\mathbf{0 . 1 3 5 4}}$ & 0.0005 & -1.4920 & 0.0020 \\
\hline
\end{tabular}

\section{Conclusions}

This study investigated the relationship between moisture supply anomalies from the MDS and the severity, duration, intensity, and peak values of meteorological drought episodes occurring over the CEU during the period 1980-2015.

A total of 51 drought episodes were identified through the one-month SPEI-1 (22 episodes with onsets during summer (April-September) and 29 events in winter (October-March)). Winter was climatologically characterized by a surplus of PRE in comparison to PET in the freshwater flux and by a peak in the moisture contribution from the MDS into the CEU.

Lagrangian forward analysis was used to investigate possible changes in the moisture contribution from the MDS to the CEU during these drought episodes. The accumulated monthly moisture supply anomaly was calculated for each drought episode, and the results obtained showed that a contribution from the MDS to the CEU for 44 cases out of the 51 episodes analyzed was negative.

A Simple Linear Regression analysis was then conducted to determine the existence of any dependent relationship between different drought episodes indicators (severity, duration, intensity, and peak values) and the contribution from the MDS. Results indicated a significant linear relationship between severity, duration, peak values (winter season), and MDS anomalies. This implied that episodes that were longer, more severe, and had a peak that was more intensive, might be associated with intensification in the moisture supply deficit from the MDS during such episodes. The highest coefficient of determination $\left(R^{2}\right)$ was found between severity of a drought episode and MDS anomalies, particularly for episodes with onsets in winter, the season when (climatologically) PRE prevailed over PET. These results showed that the severity of episodes might be modulated by variations in the moisture supply from the MDS. Nevertheless, no linear relationship was determined between the intensity and peak values (the whole period, summer season) of drought episodes and moisture contribution anomalies from the MDS.

Our findings are in agreement with previous studies that identified the MDS as the important moisture source for Europe and showed that changes in its moisture supply have an impact on dryness conditions over the region in regions where moisture sinks $[33,47,50]$. Focusing on the six-month accumulation period instead of the one-month applied here, Drumond et al. [33] have also verified a significant reduction in the moisture contribution from the MDS towards its climatological sinks (including the CEU region) during the summer and winter dry periods. In their results, anomalies in MDS evaporation presented seasonal contrasts, i.e., a reduction in winter and an increase in summer dry conditions.

The approach applied here is generally suitable for identification of linear relationships between the variability of the moisture contribution of MDS and the characteristics of the meteorological drought episodes over the CEU, which consists with the aim of this study. However, if one looks for a more realistic relationship model (e.g., for prediction purposes), it is interesting to check whether a 
non-linear relationship would fit better, as well as to consider the contribution of other sources besides the MDS.

It is important to state that for this climatological analysis, we focused on the domain-scale episodes affecting the CEU, a climatically homogeneous region defined by the IPPC, and on the impact of the MDS contribution (as a whole) for the CEU. The approach of deriving the SPEI from data averaged over the entire domain for climatological large-scale studies has been satisfactorily applied in some past studies (e.g., $[33,69,79])$. However, because each drought event is unique in terms of its temporal and spatial development, a grid point analysis would reveal not only areas more affected by dry conditions during a particular episode, but also regions particularly prone to the MDS moisture contribution. Thus, considering the intra-domain variability would be more appropriated for a detailed spatial-temporal analysis of a case.

Supplementary Materials: The following are available online at http:/ /www.mdpi.com/2073-4433/9/7/278/s1, Table S1: Drought events that occurred over Central Europe during 1980-2015; Table S2: The significance (a significance level of 95\%), slope, intercept and coefficient of determination $\left(R^{2}\right)$ for severity, duration, intensity and peak values with respect to MDS anomaly on annual, winter and summer scales of episodes classified based on duration; Table S3: The significance (a significance level of 95\%), slope, intercept and coefficient of determination $\left(R^{2}\right)$ for severity, duration, intensity and peak values with respect to MDS anomaly on annual, winter and summer scales of episodes classified based on peaks.

Author Contributions: M.S., A.D. and L.G. conceived and designed experiments. M.S. conducted experiments, and M.S., A.D. and L.G. analyzed the data. M.S., A.D., R.N. and L.G. wrote the paper.

Funding: We are grateful to the financial support from the Spanish Government (Ministerio de Economía, Industria y Competitividad) and the European Regional Development Fund of the European Commission (in Spanish, FEDER) through the SETH project (CGL2014-60849-JIN). The PhD. Fellowship of Milica Stojanovic is supported by the European Commission under the Erasmus Mundus project Green-Tech-WB: Smart and Green technologies for innovative and sustainable societies in Western Balkans (551984-EM-1-2014-1-ES-ERA Mundus-EMA2). This work was partially supported by Xunta de Galicia under Project ED431C 2017/64-GRC “Programa de Consolidación e Estruturación de Unidades de Investigación Competitivas (Grupos de Referencia Competitiva)". We would also like to thank the IMDROFLOOD project financed by the Water Works 2014 co-funded call of the European Commission.

Conflicts of Interest: The authors declare no conflicts of interest. The founding sponsors had no role in the design of the study, or in the collection, analysis or interpretation of data, or in the writing of the manuscript, or in the decision to publish the results.

\section{References}

1. Intergovernmental Panel on Climate Change (IPCC). Climate Change 2001: Impacts, Adaptation and Vulnerability; Contribution of Working Group II to the Third Assessment Report of the Intergovernmental Panel on Climate Change; Cambridge University Press: Cambridge, UK, 2001. Available online: http: //hcl.harvard.edu/collections/ipcc/docs/27_WGIITAR_FINAL.pdf (accessed on 9 July 2018).

2. Field, C.B.; Barros, V.; Stocker, T.F.; Dahe, Q. Managing the Risks of Extreme Events and Disasters to Advance Climate Change Adaptation: A Special Report of Working Groups I and II of the Intergovernmental Panel on Climate Change; Cambridge University Press: Cambridge, UK, 2012; Available online: https:/ / www.ipcc.ch/pdf/ special-reports/srex/SREX_Full_Report.pdf (accessed on 9 July 2018).

3. Lehner, B.; Döll, P.; Alcamo, J.; Henrichs, T.; Kaspar, F. Estimating the Impact of Global Change on Flood and Drought Risks in Europe: A Continental, Integrated Analysis. Clim. Chang. 2006, 75, 273-299. [CrossRef]

4. Intergovernmental Panel on Climate Change (IPCC). Climate Change 2014: Synthesis Report; Contribution of Working Groups I, II and III to the Fifth Assessment Report of the Intergovernmental Panel on Climate Change; Pachauri, R.K., Meyer, L.A., Eds.; IPCC: Geneva, Switzerland, 2014; 151p. Available online: https:/ /www. ipcc.ch/pdf/assessment-report/ar5/syr/SYR_AR5_FINAL_full_wcover.pdf (accessed on 9 July 2018).

5. Seneviratne, S.I.; Lüthi, D.; Litschi, M.; Schär, C. Land-atmosphere coupling and climate change in Europe. Nature 2006, 443, 205-209. [CrossRef] [PubMed]

6. Spinoni, J.; Vogt, J.V.; Naumann, G.; Barbosa, P.; Dosio, A. Will drought events become more frequent and severe in Europe? J. Climatol. 2017, 38, 1718-1736. [CrossRef]

7. Spinoni, J.; Naumann, G.; Vogt, V.V.; Barbosa, P. The biggest drought events in Europe from 1950-2012. J. Hydrol. 2015, 3, 509-524. [CrossRef] 
8. García-Ruiz, J.M.; López-Moreno, J.I.; Vicente-Serrano, S.M.; Lasanta-Martínez, T.; Beguería, S. Mediterranean water resources in a global change scenario. Earth Sci. Rev. 2011, 105, 121-139. [CrossRef]

9. Bates, B.C.; Kundzewicz, Z.W.; Wu, S.; Palutikof, J.P. Technical Paper of the Intergovernmental Panel on Climate Change: Climate Change Water; IPCC Secretariat: Geneva, Switzerland, 2008. Available online: https://www. ipcc.ch/pdf/technical-papers/climate-change-water-en.pdf (accessed on 9 July 2018).

10. Ionita, M.; Tallaksen, L.M.; Kingston, D.G.; Stagge, J.H.; Laaha, G.; Van Lanen, H.A.J.; Scholz, P.; Chelcea, S.M.; Haslinger, K. The European 2015 drought from a climatological perspective. Hydrol. Earth Syst. Sci. 2017, 21, 1397-1419. [CrossRef]

11. Tallaksen, L.M.; Van Lanen, H.A.J. Hydrological Drought: Processes and Estimation Methods for Streamflow and Groundwater; Developments in Water Science; Elsevier Science B.V.: Amsterdam, The Netherlands, 2004; Volume 48.

12. Bisselink, B.; Dolman, A.J. Precipitation recycling: Moisture sources over Europe using ERA-40 Data. J. Hydrometeorol. 2008, 9, 1073-1083. [CrossRef]

13. Stojanovic, M.; Drumond, A.; Nieto, R.; Gimeno, L. Anomalies in Moisture Supply during the 2003 Drought Event in Europe: A Lagrangian Analysis. Water 2018, 10, 467. [CrossRef]

14. Tsakiris, G.; Pangalou, D.; Vangelis, H. Regional drought assessment based on the Reconnaissance Drought Index (RDI). Water Resour. Manag. 2007, 21, 821-833. [CrossRef]

15. Nalbantis, I.; Tsakiris, G. Assessment of Hydrological Drought Revisited. Water Resour. Manag. 2009, 23, 881-897. [CrossRef]

16. Palmer, W.C. Meteorological Drought; White, R.M., Ed.; U.S. Weather Bureau: Washington, DC, USA, 1965. Available online: https:/ / www.ncdc.noaa.gov/temp-and-precip/drought/docs/palmer.pdf (accessed on 9 July 2018).

17. McKee, T.B.; Doesken, N.J.; Kleist, J. The relationship of drought frequency and duration to time scales. In Proceedings of the Eighth Conference on Applied Climatology, Boston, MA, USA, 17-22 January 1993; pp. 179-184.

18. Vicente-Serrano, S.M.; Begueria, S.; Lopez-Moreno, J.I. A multiscalar drought index sensitive to global warming: The Standardized Precipitation Evapotranspiration Index. J. Clim. 2010, 23, 1696-1718. [CrossRef]

19. Onyutha, C. On Rigorous Drought Assessment Using Daily Time Scale: Non-Stationary Frequency Analyses, Revisited Concepts, and a New Method to Yield Non-Parametric Indices. Hydrology 2017, 4, 48. [CrossRef]

20. Sordo-Ward, A.; Dolores Bejarano, M.; Iglesias, A.; Asenjo, V.; Garrote, L. Analysis of Current and Future SPEI Droughts in the La Plata Basin Based on Results from the Regional Eta Climate Model. Water 2017, 9 , 857. [CrossRef]

21. Meza, F.J. Recent trends and ENSO influence on droughts in Northern Chile: An application of the standardized precipitation evapotranspiration index. Weather Clim. Extrem. 2013, 1, 51-58. [CrossRef]

22. Mathbout, S.; Lopez-Bustins, J.A.; Martin-Vide, J.; Bech, J.; Rodrigo, F.S. Spatial and temporal analysis of drought variability at several time scales in Syria during 1961-2012. Atmos. Res. 2018, 200, 153-168. [CrossRef]

23. Wang, R.; Peng, W.; Liu, X.; Wu, W.; Chen, X.; Zhang, S. Responses of Water Level in China's Largest Freshwater Lake to the Meteorological Drought Index (SPEI) in the Past Five Decades. Water 2018, 10, 137. [CrossRef]

24. Salah, Z.; Nieto, R.; Drumond, A.; Gimeno, L.; Vicente-Serrano, S.M. A Lagrangian analysis of the moisture budget over the Fertile Crescent during two intense drought episodes. J. Hydrol. 2018, 560, 382-395. [CrossRef]

25. Hassanein, M.K.; Kahlil, A.A.; Essa, Y.H. Assessment of drought impact in Africa using Standard Precipitation Evapotranspiration Index. Nat. Sci. 2013, 11, 75-81. Available online: https://www. researchgate.net/publication/283615625 (accessed on 9 July 2018).

26. Potop, V.; Boroneant, C.; Stepanek, P.; Skalak, P.; Mozný, M. Observed spatiotemporal characteristics of drought on various time scales over the Czech Republic. Theor. Appl. Climatol. 2013, 115, 563-581. [CrossRef]

27. Paulo, A.A.; Rosa, R.D.; Pereira, L.S. Climate trends and behaviour of drought indices based on precipitation and evapotranspiration in Portugal. Nat. Hazards Earth Syst. Sci. 2012, 12, 1481-1491. [CrossRef] 
28. Vicente-Serrano, S.M.; López-Moreno, J.I.; Lorenzo-Lacruz, J.; El Kenawy, A.; Azorin-Molina, C.; Morán-Tejeda, E.; Pasho, E.; Zabalza, J.; Begueria, S.; Angulo-Martinez, M. The NAO impact on droughts in the Mediterranean region. In Hydrological, Socioeconomic and Ecological Impacts of the North Atlantic Oscillation in the Mediterranean Region-Advances in Global Change Research; Springer: Rotterdam, The Netherlands, 2011; Volume 46, pp. 23-40. [CrossRef]

29. Potopová, V.; Boroneat, C.; Boincean, B.; Soukup, J. Impact of agricultural drought on main crop yields in the Republic of Moldova. Int. J. Climatol. 2016, 36, 2063-2082. [CrossRef]

30. Spinoni, J.; Naumann, G.; Vogt, J.V.; Barbosa, P. European drought climatologies and trends based on a multi-indicator approach. Glob. Planet. Chang. 2015, 127, 50-57. [CrossRef]

31. Peterson, T.C.; Hoerling, M.P.; Stott, P.A.; Herring, S.C. (Eds.) Explaining Extreme Events of 2012 from a Climate Perspective. Bull. Am. Meteorol. Soc. 2013, 94, S1-S74. [CrossRef]

32. Sori, R.; Nieto, R.; Vicente-Serrano, S.M.; Drumond, A.; Gimeno, L. A Lagrangian perspective of the hydrological cycle in the Congo River Basin. Earth Syst. Dyn. 2017, 8, 653-675. [CrossRef]

33. Drumond, A.; Gimeno, L.; Nieto, R.; Trigo, R.M.; Vicente-Serrano, S.M. Drought episodes in the climatological sinks of the Mediterranean moisture source: The role of moisture transport. Glob. Planet. Chang. 2017, 151, 4-14. [CrossRef]

34. Gimeno, L.; Stohl, A.; Trigo, R.M.; Domínguez, F.; Yoshimura, K.; Yu, L.; Drumond, A.; Durán-Quesada, A.M.; Nieto, R. Oceanic and Terrestrial Sources of Continental Precipitation. Rev. Geophys. 2012, 50, RG4003. [CrossRef]

35. Gimeno, L.; Drumond, A.; Nieto, R.; Trigo, R.M.; Stohl, A. On the origin of continental precipitation. Geophys. Res. Lett. 2010, 37, L13804. [CrossRef]

36. Stohl, A.; James, P. A Lagrangian Analysis of the Atmospheric Branch of the Global Water Cycle. Part I: Method Description, Validation, and Demonstration for the August 2002 Flooding in Central Europe. J. Hydrometeorol. 2004, 5, 656-678. [CrossRef]

37. Stohl, A.; James, P. A Lagrangian analysis of the atmospheric branch of the global water cycle: Part II: Moisture Transports between Earth's Ocean Basins and River Catchments. J. Hydrometeorol. 2005, 6, 961-984. [CrossRef]

38. Mariotti, A.; Struglia, M.V.; Zeng, N.; Lau, K.M. The Hydrological Cycle in the Mediterranean Region and Implications for the Water Budget of the Mediterranean Sea. J. Clim. 2002, 15, 1674-1690. [CrossRef]

39. Bosilovich, M.G.; Schubert, S.D. Water vapor tracers as diagnostics of the regional hydrologic cycle. J. Hydrometeorol. 2002, 3, 149-165. [CrossRef]

40. Brubaker, K.L.; Entekhabi, D.; Eagleson, P. Estimation of continental precipitation recycling. J. Clim. 1993, 6, 1077-1089. [CrossRef]

41. Dominguez, F.; Kumar, P.; Liang, X.-Z.; Ting, M. Impact of atmospheric moisture storage on precipitation recycling. J. Clim. 2006, 19, 1513-1530. [CrossRef]

42. Coplen, T.B.; Neiman, P.J.; White, A.B.; Landwehr, J.M.; Ralph, F.M.; Dettinger, M.D. Extreme changes in stable hydrogen isotopes and precipitation characteristics in a landfalling Pacific storm. Geophys. Res. Lett. 2008, 35, L21808. [CrossRef]

43. Sodemann, H.; Schwierz, C.; Wernli, H. Interannual variability of Greenland winter precipitation sources: Lagrangian moisture diagnostic and North Atlantic Oscillation influence. J. Geophys. Res. 2008, 113, D03107. [CrossRef]

44. Dirmeyer, P.A.; Brubaker, K.L. Characterization of the global hydrologic cycle from a back-trajectory analysis of atmospheric water vapor. J. Hydrometeorol. 2007, 8, 20-37. [CrossRef]

45. Fernandez, J.; Saenz, J.; Zorita, E. Analysis of winter time atmospheric moisture transport and its variability over Southern Europe in the NCEP-reanalyses. Clim. Res. 2003, 23, 195-215. [CrossRef]

46. Nieto, R.; Gimeno, L.; Drumond, A.; Hernandez, E. A Lagrangian identification of the main moisture 344 sources and sinks affecting the Mediterranean area. WSEAS Trans. Environ. Dev. 2010, 6, 1790-5079. Available online: http:/ / ephyslab.uvigo.es/publica/documents/file_23740-A\%20Lagrangian\% 20identification $\% 20$ of $\% 20$ the $\% 20$ main $\% 20$ moisture $\% 20$ sources $\% 20$ and $\% 20 \operatorname{sinks} \% 20$ affecting $\% 20$ the $\%$ 20Mediterranean\%20area-WSEAS-2010.pdf (accessed on 9 July 2018).

47. Schicker, I.; Radanovics, R.; Seibert, P. Origin and transport of Mediterranean moisture and air. Atmos. Chem. Phys. 2010, 10, 5089-5105. [CrossRef] 
48. Drumond, A.; Nieto, R.; Hernández, E.; Gimeno, L. A Lagrangian analysis of the variation in moisture sources related to drier and wetter conditions in regions around the Mediterranean basin. Nat. Hazards Earth Syst. Sci. 2011, 11, 2307-2320. [CrossRef]

49. Gómez-Hernández, M.; Drumond, A.; Gimeno, L.; Garcia-Herrera, R. Variability of moisture sources in the Mediterranean region during the period 1980-2000. Water Resour. Res. 2013, 49, 6781-6794. [CrossRef]

50. Sodemann, H.; Zubler, E. Seasonal and inter-annual variability of the moisture sources for Alpine precipitation during 1995-2002. Int. J. Climatol. 2010, 30, 947-961. [CrossRef]

51. Lionello, P.; Malanotte-Rizzoli, P.; Boscolo, R.; Alpert, P.; Artale, V.; Li, L.; Luterbacher, J.; May, W.; Trigo, R.; Tsimplis, M.; et al. The Mediterranean climate: An overview of the main characteristics and issues. Dev. Earth Environ. Sci. 2006, 4, 1-26. [CrossRef]

52. Ciric, D.; Nieto, R.; Losada, L.; Drumond, A.; Gimeno, L. The Mediterranean Moisture Contribution to Climatological and Extreme Monthly Continental Precipitation. Water 2018, 4, 519. [CrossRef]

53. Kyselý, J.; Beranová, R. Climate-change effects on extreme precipitation in central Europe: Uncertainties of scenarios based on regional climate models. Theor. Appl. Climatol. 2009, 95, 361-374. [CrossRef]

54. Dee, D.P.; Uppala, S.M.; Simmons, A.J.; Berrisford, P.; Poli, P.; Kobayashi, S.; Andrae, U.; Balmaseda, M.A.; Balsamo, G.; Bauer, P.; et al. The ERA-Interim reanalysis: Configuration and performance of the data assimilation system. Q. J. R. Meteorol. Soc. 2001, 137, 553-597. [CrossRef]

55. Lorenz, C.; Kunstmann, H. The hydrological cycle in three state-of-the-art reanalyses: Intercomparison and performance analysis. J. Hydrometeorol. 2012, 13, 1397-1420. [CrossRef]

56. Rienecker, M.; Suarez, M.; Gelaro, R.; Todling, R.; Bacmeister, J. Co-authors, 2011: MERRA: NASA's Modern Era Retrospective Analysis for Research and Applications. J. Clim. 2014, 24, 3624-3648. [CrossRef]

57. National Center for Atmospheric Research Staff (Ed.) Last modified 08 November 2017. "The Climate Data Guide: Climate Forecast System Reanalysis (CFSR)". Available online: https: / climatedataguide.ucar.edu/ climate-data/climate-forecast-system-reanalysis-cfsr (accessed on 9 July 2018).

58. Gimeno, L.; Nieto, R.; Drumond, A.; Castillo, R.; Trigo, R.M. Influence of the intensification of the major oceanic moisture sources on continental precipitation. Geophys. Res. Lett. 2013, 40, 1443-1450. [CrossRef]

59. Harris, I.; Jones, P.D.; Osborn, T.J.; Lister, D.H. Updated high-resolution grids of monthly climatic observations-The CRU TS3.10 Dataset. Int. J. Climatol. 2014, 34, 623-642. [CrossRef]

60. Yu, L.; Jin, X.; Weller, R.A. Multidecade Global Flux Datasets from the Objectively Analyzed Air-Sea Fluxes (OAFlux) Project: Latent and Sensible Heat Fluxes, Ocean Evaporation, and Related Surface Meteorological Variables; OAFlux Project Tech. Rep. OA-2008-01; Woods Hole Oceanographic Institution: Woods Hole, MA, USA, 2008; 64p. Available online: http:/ / oaflux.whoi.edu/pdfs/OAFlux_TechReport_3rd_release.pdf (accessed on 9 July 2018).

61. Stagge, J.A.; Tallaksen, L.M.; Gudmundsson, L.; Van Loon, A.F.; Stahle, K. Candidate distributions for climatological drought indices (SPI and SPEI). Int. J. Climatol. 2015, 35, 4027-4040. [CrossRef]

62. Stagge, J.A.; Tallaksen, L.M.; Gudmundsson, L.; Van Loon, A.F.; Stahle, K. Short communication response to comment on Candidate Distributions for Climatological Drought Indices (SPI and SPEI). Int. J. Climatol. 2016, 36, 2132-2138. [CrossRef]

63. Vicente-Serrano, S.M.; Beguería, S. Short communication comment on "candidate distributions for climatological drought indices (SPI and SPEI)" by James H. Stagge et al. Int. J. Climatol. 2016, 36, 2120-2131. [CrossRef]

64. Vicente-Serrano, S.M.; Gouveia, C.; Camarero, J.J.; Beguería, S.; Trigo, R.; López-Moreno, J.I.; Azorín-Molina, C.; Pasho, E.; Lorenzo-Lacruz, J.; Revuelto, J.; et al. Response of vegetation to drought time-scales across global land biomes. Proc. Natl. Acad. Sci. USA 2013, 110, 52-57. [CrossRef] [PubMed]

65. Vicente-Serrano, S.M.; Aguilar, E.; Martínez, R.; Martín-Hernández, N.; Azorin-Molina, C.; Sanchez-Lorenzo, A.; El Kenawy, A.; Tomás-Burguera, M.; Moran-Tejeda, E.; López-Moreno, J.I.; et al. The Complex influence of ENSO on droughts in Ecuador. Clim. Dyn. 2016, 48, 405-427. [CrossRef]

66. Vicente-Serrano, S.M.; Beguería, S.; López-Moreno, J.I. Comment on "Characteristics and trends in various forms of the Palmer Drought Severity Index (PDSI) during 1900-2008” by A. Dai. J. Geophys. Res. Atmos. 2011, 116, D19112. [CrossRef]

67. Beguería, S.; Vicente-Serrano, S.M.; Reig, F.; Latorre, B. Standardized Precipitation Evapotranspiration Index (SPEI) revisited: Parameter fitting, evapotranspiration models, tools, datasets and drought monitoring. Int. J. Climatol. 2014, 34, 3001-3023. [CrossRef] 
68. Liu, Z.; Lu, G.; He, H.; Wu, Z.; He, J. Anomalous Features of Water Vapor Transport during Severe Summer and Early Fall Droughts in Southwest China. Water 2017, 9, 244. [CrossRef]

69. Stojanovic, M.; Drumond, A.; Nieto, R.; Gimeno, L. Moisture Transport Anomalies over the Danube River Basin during Two Drought Events: A Lagrangian Analysis. Atmosphere 2017, 8, 193. [CrossRef]

70. Brázdil, R.; Raška, P.; Trnka, M.; Zahradníček, P.; Valášek, H.; Dobrovolný, P.; Řezníčková, L.; Treml, P.; Stachoň, Z. The central European drought of 1947: Causes and consequences, with particular reference to the Czech Lands. Clim. Res. 2016, 70, 161-178. [CrossRef]

71. Tan, C.; Yang, J.; Li, M. Temporal-Spatial Variation of Drought Indicated by SPI and SPEI in Ningxia Hui Autonomous Region, China. Atmosphere 2015, 6, 1399-1421. [CrossRef]

72. Spinoni, J.; Naumann, G.; Carrao, H.; Barbosa, P.; Vogt, J. World drought frequency, duration, and severity for 1951-2010. Int. J. Climatol. 2014, 34, 2792-2804. [CrossRef]

73. Numaguti, A. Origin and recycling processes of precipitating water over the Eurasian continent: Experiments using an atmospheric general circulation model. J. Geophys. Res. Atmos. 1999, 104, 1957-1972. [CrossRef]

74. Ciric, D.; Stojanovic, M.; Drumond, A.; Nieto, R.; Gimeno, L. Tracking the Origin of Moisture over the Danube River Basin Using a Lagrangian Approach. Atmosphere 2016, 7, 162. [CrossRef]

75. Duran-Quesada, A.M.; Gimeno, L.; Amador, J.A.; Nieto, R. Moisture sources for Central America: Identification of moisture sources using a Lagrangian analysis technique. J. Geophys. Res. 2010, 115, D05103. [CrossRef]

76. Nieto, R.; Gimeno, L.; Gallego, D.; Trigo, R.M. Contributions to the moisture budget of airmasses over Iceland. Meteorol. Z. 2007, 16, 37-44. [CrossRef]

77. Sori, R.; Nieto, R.; Drumond, A.; Vicente-Serrano, S.M.; Gimeno, L. The atmospheric branch of the hydrological cycle over the Indus, Ganges, and Brahmaputra river basins. Hydrol. Earth Syst. Sci. 2017, 21, 6379-6399. [CrossRef]

78. Zar, J.H. Significance testing of the Spearman rank correlation. J. Am. Stat. Assoc. 1972, 67, 578-580. [CrossRef]

79. Drumond, A.; Nieto, R.; Gimeno, L. A Lagrangian approach for investigating anomalies in the moisture transport during drought episodes. Cuadernos de Investigación Geográfica 2016, 42, 113-125. [CrossRef] 